\title{
NOSTALGIA, REVIVAL Y MÚSICAS POPULARES EN EL ÚLTIMO GINE ESPAÑOL
}

\author{
Teresa Fraile Prieto
}

Universidad de Extremadura

\section{NOSTALGIA, MÚSICA Y CINE}

La primera década del siglo XXI ha visto surgir en el cine español un fenómeno de recuperación de canciones del periodo franquista. Sobre todo de aquellas canciones de la época de esplendor del cine musical de los sesenta y los setenta, protagonizado por estrellas como Marisol, Rocío Dúrcal o Raphael. Películas como 20 centímetros, Torremolinos 73 o Vivir es fácil con los ojos cerrados y especialmente las bandas sonoras de las películas dirigidas por Álex de la Iglesia, se convierten en textos nostálgicos al hacer alusión al pasado a través de recursos estilísticos. Las músicas de estas producciones son a un tiempo rastro del pasado y seña de nuestro presente, en tanto que sus canciones forman parte del proceso cultural por el cual el canon del pop ha sido redimensionado como parte de nuestra aproximación al pasado estilizado. En el actual contexto español, este revival contribuye a la creación de cierta identidad nacional, postmoderna y glocal.

Antes de analizar detenidamente este fenómeno a nivel nacional, conviene detenerse en el papel que a lo largo del tiempo ha jugado la música en la construcción de la nostalgia en el cine. Según Claudia Gorman y Caryl Flinn, puede compararse la idea de nostalgia, que tradicionalmente ha dominado la composición de aquella banda sonora que privilegia la invisibilidad del mecanismo fílmico, con esa otra noción de nostalgia aportada por las canciones preexistentes que son insertadas en el cine.

Dentro del mecanismo fílmico, la música se ha estandarizado como un elemento más, de tal manera que es habitual escuchar una base de acompañamiento instrumental, en muchas ocasiones un fondo perpetuo de música orquestal, que subraya emocionalmente cada acontecimiento de la película. Los cimientos de esta práctica se remontan al periodo clásico de la composición para cine, en los años treinta y cuarenta del cine de Hollywood, donde la estructura de producción en cadena de los grandes estudios integró a muchos de los compositores de Broadway y a otros europeos que venían huyendo de la situación política de sus lugares de origen, y que trajeron consigo las maneras de componer propias de las óperas de Wagner o los poemas sinfónicos de Richard Strauss. Este estilo musical postromántico, melódico y 
lírico, es el que escuchamos aún hoy en muchas producciones. Con más razón si tenemos en cuenta que este tipo de ambientación musical facilita la comprensión unidireccional de la trama, ayuda a la audiencia a sumergirse en el relato, aporta continuidad narrativa y hace olvidar cualquier rastro de técnica cinematográfica.

Claudia Gorbman (1987) plantea el estudio de la música cinematográfica del Hollywood clásico desde la reflexión sobre su voluntad ideológica. En primer lugar, Gorbman propone que la música en el cine es un elemento inverosímil, impensable en la realidad, pero que se vuelve necesario y altamente eficaz en la construcción fílmica porque conecta con los resortes psíquicos de la audiencia de forma inconsciente; es decir, estas músicas se convierten en "melodías inaudibles" en tanto que no son escuchadas conscientemente, pero funcionan activamente gracias a su subordinación a la narración. Es más, la música afianza la identificación del público con el contenido del film y lo adormece en una especie de estado hipnótico, por tanto asegura la recepción de los significados procurados por la película y convierte a la audiencia en sujetos "menos críticos y un poco más propensos a soñar" (Gorbman, 1987: 55). En consecuencia, si la nostalgia es el dolor por la ausencia de mundos utópicos no presentes, la música es un buen aliado en la huida hacia los mundos propuestos por el cine.

En esto enlaza con las tesis sostenidas por Caryl Flinn en Strains of Utopia (Flinn, 1992), para quien la música se revela como un extraordinario recurso para transportar al público a un mundo utópico. El cine hollywoodiense está impregnado de ideología romántica, que concuerda a la perfección con el estilo musical postromántico utilizado, por cuanto dicha corriente concibe la música como una expresión atemporal que transmite directamente las emociones humanas. Desde esta perspectiva, la música fue un factor definitivo en las películas de la época clásica del cine norteamericano, que presentaban un futuro perfecto o permitían a los espectadores evadirse hacia un pasado idealizado, en un momento de paulatino crecimiento del capitalismo, porque, gracias a su conexión con la afectividad y lo transcendente, la música activaba la nostalgia del espectador por ese mundo perdido.

Sin embargo, este funcionamiento musical dirigido a la distracción, característico del modelo hollywoodiense y aún hoy día muy vivo en grandes producciones, no es el único que actúa como llamada a la nostalgia. Otras perspectivas ponen el enfoque en la concepción de la nostalgia, o más concretamente, en las utilizaciones del pasado, características de la postmodernidad. Fredric Jameson sostiene que en la era postmoderna el pasado ha sido convertido en mercancía, y ha pasado a ser "un vasto conjunto de imágenes, un ingente simulacro fotográfico" (Jameson, 1991: 10), por lo que el pasado solamente existe como recreación y la historia ha sido sustituida por una sucesión de estilos estéticos. En la misma línea, Linda Hutcheon (1998), en uno de los textos más emblemáticos sobre la nostalgia posmoderna, la señala como una de las características más destacadas de la postmodernidad. Según Hutcheon, es la nostalgia la que empuja a construir el pasado como la proyección de un tiempo ideal, carente de los problemas del presente: el artificioso proceso de selección de momentos recordados, distorsionados, escogidos e incluso olvidados nos devuelve el pasado como algo coherente, estable, cerrado, sencillo y armónico, mientras nos aleja del presente.

El mencionado proceso postmoderno de reconstrucción del pasado es fácilmente reconocible en películas que ponen al descubierto el mecanismo cinematográfico, rompiendo el dispositivo de sutura de la época clásica y jugando con la elaboración de un discurso artificial. Por ejemplo, son multitud las películas que reutilizan imágenes documentales para insertarlas en la narrativa: recordemos el paradigmático caso de Tom Hanks dando la mano al presidente 
Kennedy (Forrest Gump, Robert Zemeckis, 1994) o a Clint Eastwood como su guardaespaldas (In the line of Fire, Wolfgang Petersen, 1993) o, en el ámbito nacional, a Penélope Cruz al lado de The Beatles en El amor perjudica seriamente la salud (Gómez Pereira, 1996), a Javier Cámara con John Lennon en Vivir es fácil con los ojos cerrados (David Trueba, 2013) o a Santiago Segura desfilando junto al príncipe Felipe en la inauguración de los Juegos Olímpicos de Barcelona'92, e incluso lanzando la flecha al pebetero, en Muertos de risa (Álex de la Iglesia, 1999).

Para ilustrar esta tendencia también resulta muy clarificador reflexionar sobre aquellas bandas sonoras formadas por una compilación de canciones preexistentes, lo cual es una práctica más habitual desde los años setenta. Al igual que las imágenes de archivo, las canciones resultan muy útiles en los procesos de evocación, pues añaden múltiples significados extradiegéticos vinculados a contextos históricos concretos. Además, mientras la música incidental, en la mayoría de los casos compuesta expresamente para la película, pretende pasar inadvertida como background, la música popular preexistente se sitúa en primer plano. El uso de canciones previas en el cine se deriva de una doble voluntad nostálgica: por un lado el cineasta recurre a ellas apelando a su recuerdo personal, biográfico, individual, y por otro las canciones enlazan con la nostalgia colectiva, aludida previamente, por la que la sociedad de un presente elabora recuerdos ficticios de un pasado. Así, estas bandas sonoras se convierten también en la de "una edad de oro perdida" (Tincknell, 2006: 135), aunque reciente, que no es sino un síntoma de las angustias más actuales.

\section{LA RECUPERACIÓN DE LOS AÑOS SESENTA, SETENTA Y OCHENTA EN EL ÚLTIMO CINE ESPAÑOL}

Son innumerables las construcciones fílmicas que echan una mirada al pasado en el cine español. Desde las revisiones del periodo de la Guerra Civil y los sórdidos años del franquismo hasta la convulsa Transición y nuestro pasado más reciente, la historia compartida ha sido revisitada incontables veces desde distintos enfoques cinematográficos. Desde finales de los años noventa se ha reavivado extraordinariamente el fenómeno de vuelta al pasado, tanto en los medios de comunicación como en la literatura, insistiendo casi siempre en visiones de la historia relatadas a través de vivencias personales y desde percepciones muy individuales. Así ocurre en la célebre serie de Televisión Española Cuéntame, en antena desde 2001, pero también en las experiencias vitales de variopintos personajes narradas en El amor perjudica seriamente la salud (Gómez Pereira, 1996), Días de cine (David Serrano, 2007), Los años desnudos. Clasificada S (Dunia Ayaso y Félix Sabroso, 2008), o la alabada Madrid, 1987 (David Trueba, 2011), por mencionar solo algunos ejemplos.

Es más, en muchos casos estas películas son un fruto evidente del presente, pues plantean problemas y conflictos de total actualidad. Como afirma Benet a propósito de las películas sobre la Guerra Civil -aludiendo por ejemplo a Libertarias (Vicente Aranda, 1996) o Soldados de Salamina (David Trueba, 2002)-, "en lugar de intentar articular el pasado como problema histórico o incluso como estrategia de recuperación de la memoria, estos filmes se someten a las necesidades y visiones del presente" (Benet, 2012: 412).

En estas producciones retro, se tiende al rescate nostálgico de costumbres, imágenes, dichos, objetos cotidianos y, por supuesto, músicas provenientes de los más diversos rincones de la cultura popular de la modernidad nacional. Casi en todos los casos, los autores de estas películas son aquellos cuyo imaginario, por una cuestión generacional, se ha nutrido del 
cine, los comics, la publicidad, los vídeos musicales, la televisión, la radio y las canciones de esa época. Dicha memoria audiovisual, utilizada en ocasiones en forma de nostalgia, otras en forma de pastiche cultural, es compartida con la audiencia, que posee la competencia cultural necesaria para participar de los códigos y descifrar el discurso propuesto en estas obras.

Siendo más precisos, habría que diferenciar aquellas películas que tratan sobre el pasado de las que utilizan elementos del pasado. Dentro de la primera categoría, caben las alusiones que el cine español ha hecho a la década de los años sesenta en películas como El amor perjudica seriamente la salud (Manuel Gómez Pereira, 1996), que comienza su relato en la visita de los Beatles a España en 1965 y lo termina en la España democrática de los años noventa. Igualmente, Vivir es fácil con los ojos cerrados, cuyo título proviene de un verso de la canción de The Beatles "Strawberry Fields Forever", relata el viaje de un profesor de inglés a Almería a mediados de los sesenta para conocer a John Lennon, que está rodando allí Cómo gané la guerra (Richard Lester, 1967). La ambientación musical diegética hace acopio del pop de la época, si bien su uso más destacado aparece en una escena de sexo iniciático entre los jóvenes autoestopistas que Antonio recoge en su viaje. En esta secuencia utiliza el tema "Mejor" de Los Brincos, uno de los conjuntos musicales más exitosos de los años sesenta, publicitados como los Beatles españoles. A pesar del tono festivo de la canción, la letra habla de un desengaño amoroso, aludiendo a la decepción que la joven Belén experimenta después de la ilusión de un primer amor.

Del mismo modo, los años setenta y ochenta han sido retomados en películas actuales, igual que ya lo hiciera Pedro Almodóvar. Por nombrar sólo alguna de las referencias al pasado quasi-biográfico del director manchego, Carne Trémula (Almodóvar, 1997) comienza en el mes de enero de 1970 y transcurre en los años de la Transición, explicando desde la piel de sus protagonistas el transcurso de su vida en el decorado de la España de la recién conquistada libertad. El mismo Almodóvar, no sólo en sus primeras películas sino también en las más recientes, ha seguido haciendo alusión a ese fenómeno cultural y musical de los años ochenta bautizado como la Movida, revisitado en todos los ámbitos de la comunicación mediática, desde la ya citada serie Cuéntame, hasta la película El Calentito (Chus Gutiérrez, 2005) ${ }^{1}$.

Pero actualmente, además de esta perspectiva en la que la evolución política y social de España es característica de las vivencias de una generación, progresivamente han surgido otras visiones menos individualizadas, menos festivas y más sórdidas que las de años precedentes, en las cuales la historia se problematiza y se plantean visiones críticas de los hechos ocurridos en la Transición, sugiriendo la continuidad de los valores del franquismo y la nueva derrota de los perdedores de la Guerra mediante el pacto del olvido. En esta línea se sitúa 23-F: la película (Chema de la Peña, 2011) y en cierto modo también el cine de Álex de la Iglesia por cuanto, en tono de comedia negra, pinta la historia cercana de España como un periodo oscuro plagado de incertidumbres.

El retrato del cine realizado en aquellos años también ha servido para relatar en tono agrio y desencantado nuestra historia. Varios son los cineastas que recurren a la nostalgia por el propio cine, como ya hiciera David Trueba en Obra maestra (2000) al inventar los fracasos de dos directores de cine aficionados que quieren rodar en Súper 8 una película musical. Asimismo, Pablo Berger, el director del corto Mamá (1988) en el que Álex de la Iglesia se inicia

1 El fenómeno de recuperación de signos populares de la década de los ochenta es en realidad más amplio y engloba reposiciones de series de televisión (Verano azul, El superhéroe americano), la vuelta al escenario de grupos musicales (Hombres G, La Guardia), programas televisivos y concursos de conocimientos (Ochéntame otra vez, Los mejores años de nuestra vida) o campañas publicitarias (Coca-Cola, Minut Maid, Bankia). 
en el cine como director artístico, hará muchos años más tarde Torremolinos 73 (2003). En esta película un vendedor de enciclopedias y cineasta de poca monta, con ínfulas de Ingman Bergman, se ve abocado a realizar películas porno caseras. Enmarcando las peripecias de los personajes, además de la música incidental compuesta por Nacho Mastreta, se escuchan muchos de los temas musicales que estaban de moda en los comienzos de los años setenta: así aparecen "Mammy blue" de los Pop Tops, "Eva María" de Fórmula V, "Help, ayúdame" de Tony Ronald, "Palomitas de maíz" de Los Pekenikes, "Eres tú" de Mocedades, "Carmen" interpretada por Trébol e incluso una versión de "Un rayo de sol" de Los Diablos cantada en inglés por Doctor Explosion. Algo menos lograda, Los años desnudos (Dunia Ayaso y Félix Sabroso, 2008) aborda el cine $\mathrm{S}$ de los setenta a través de la historia de tres actrices, ambientando la narración en el mundillo del cine del destape, el imaginario de la televisión, y recurriendo a una banda sonora que incluye música disco de la época y otras curiosidades como "Algo de mí" de Camilo Sesto, "Acaríciame" interpretada por Susana Estrada y un "Aún vivo para el amor" interpretada por Fernando Fernán Gómez.

En referencia a la segunda categoría, aquellas producciones que reutilizan artefactos del pasado dentro de narrativas del presente, destaca el fenómeno del cine musical. Bien es cierto que no se trata del musical norteamericano al uso sino de la versión pasada por el tamiz de lo hispano, que recurre en igual medida a códigos estructurales del musical clásico y a referencias a escenarios locales de España y sus personajes autóctonos.

Es habitual que los números musicales de estas películas estén construidos sobre canciones del pop de los ochenta, como pasa en El otro lado de la cama (2002) y su secuela Los dos lados de la cama (2005), de Emilio Martínez-Lázaro. Precisamente, en estas dos comedias de enredos de parejas los actores cantan y bailan versiones de "Las chicas son guerreras" (Coz, 1981), "Dime que me quieres", "Salta", "Quiero besarte" (Tequila, 1980 y 1981), "Bailando" (Alaska y Los Pegamoides, 1982), "Ay, qué pesado" (Mecano, 1986), "Déjame" (Los Secretos, 1980) o "Quiero un camión" ("Loquillo", 1983). Las razones por las cuales se eligen los temas musicales tienen que ver con la conveniencia de la letra y con que son reconocibles para una gran parte de la audiencia, de la misma manera que en el musical clásico. De forma que no atienden al tiempo diegético de la narración, pues no corresponden al momento histórico de la película, sino a la nostalgia colectiva y al pasado común del público.

Otros musicales toman canciones de varias décadas y géneros, pero con propósitos similares. 20 centímetros (Ramón Salazar, 2005) es la historia de Marieta, transexual que está ahorrando para realizarse la última operación de cambio de sexo. En sus ataques de narcolepsia se sueña a sí misma en números musicales que ilustran la narrativa, de manera que podemos oír desde "I want to break free" de Queen, "True blue" de Madonna, "Changes" de David Bowie, a las canciones patrias "Piel canela", "Verde que te quiero verde", y otras conocidas en la España de los sesenta como "Quiero" de Salvatore Adamo, de los setenta como "Parole, parole" (popularizada por Mina) o de los ochenta como "Quiero ser santa" de Parálisis Permanente; aunque el número musical más recordado es el homenaje a las películas de Marisol, en el que Marieta canta "Tómbola" y "Muchachita" por la Gran Vía de Madrid.

¿Por qué se frotan las patitas? (Álvaro Begines, 2006) es un extraño caso eminentemente español por cuanto se ambienta en Andalucía y unifica las canciones recuperadas, de distintas procedencias, bajo el estilo flamenco y sus sucedáneos, si bien la estructura sigue siendo la del musical. Escuchamos versiones aflamencadas para números musicales coreográficos de "Soy rebelde" de Janette (1971) que canta India Martínez por bulerías por soleá, "Vivir así 
es morir de amor" de Camilo Sesto (1978) en la versión de India Martínez y José Ángel Carmona, "Escándalo" de Raphael (1991) interpretada por Carmen Linares por bulerías, "Loco" de Calamaro (1997) cantada por José Ángel Carmona, y el "Aserejé" que popularizaron las Ketchup en el año 2000 rapeado por Tomasito.

\section{MÚSICAS POPULARES EN EL CINE DE ÁLEX DE LA IGLESIA}

A fin de acercarnos de una manera más efectiva al fenómeno del revival musical en el cine español reciente, vamos a poner la lupa en el caso concreto Álex de la Iglesia, uno de los estandartes del grupo de realizadores vascos que aparecieron en la escena del cine a finales de los años ochenta y comienzos de los noventa. Además de por una extensa filmografía de, hasta la fecha, once largometrajes ${ }^{2}$, varios cortometrajes, trabajos para televisión y una novela, se le recuerda por ser el presidente de la Academia de las Artes y las Ciencias Cinematográficas de España durante dos convulsos años en los que la cinematografía nacional se veía envuelta en el debate de la crisis económica y los nuevos soportes de consumo audiovisual.

El humor negro es su marca de fábrica, saltando de la comedia al horror sin solución de continuidad, en películas, en la mayoría de los casos, definidas por una violencia muy explícita y a veces brutal. El humor y la violencia se muestran como dos caras de la misma moneda, lo que le permite insertar la violencia con cierto distanciamiento y ligera sorna, y el humor con un innegable toque trágico. En consecuencia, sus personajes son mayoritariamente perdedores en situaciones límite, que en cierto momento intentan escapar de manera furiosa a esa condición, o bien, vengarse. Aunque su sello es tan personal que podría considerarse cine de autor en el sentido tradicional, de la Iglesia está profundamente atado a los géneros, que mezcla sin tapujos desde el humor, en unas historias vinculadas tanto con el cine de terror como con la comedia y en otras ocasiones con el western, la ciencia-ficción o la roadmovie.

El cine de este director puede definirse como abigarrado y casi sobrecargado, plagado de referentes tan diversos como su imaginario, compuesto por elementos absorbidos del comic (en el que se inició como creador), de una dilatada cultura cinematográfica y de cualquier elemento que apareciera en la bizarra pantalla de la televisión nacional desde la década de los setenta. Porque dicha desmesurada cantidad de referencias se debe en parte a la influencia recibida de la televisión. Él mismo afirma: "Daos cuenta de que la televisión era el agujero a través del cual veíamos el universo durante esos años. Una extraña lente hacía que convergieran en ella cosas imposibles de unir. Ahí está el germen de esta especie de eclecticismo o de confusión mental en el que vivimos desde entonces" (Angulo, 2012: 109). Puede que ahí se encuentre también el origen de su fijación por romper la barrera entre lo que tradicionalmente se ha entendido por alta y baja cultura, y una querencia hacia los códigos, fenómenos y referentes de la cultura popular.Dentro de este eclecticismo, la música en general, y las canciones preexistentes en particular, tienen mucha presencia en el cine de Álex de la Iglesia ${ }^{3}$, siempre empleadas desde la ironía o para invertir su significado origi-

2 Acción mutante (1992), El día de la bestia (1995), Perdita Durango (1997), Muertos de risa (1999), La comunidad (2000), 800 balas (2002), Crimen ferpecto (2004), Los crímenes de Oxford (2008), Balada triste de trompeta (2010), La chispa de la vida (2011) y Las brujas de Zugarramurdi (2012).

3 En la música incidental, Álex de la Iglesia ha trabajado con diversos compositores. El músico que más asiduamente ha colaborado en sus películas es el polifacético Roque Baños, que empieza con él en Muertos de risa (1999) y compone también la música de La comunidad (2000), 800 balas (2002), Crimen ferpecto (2004), La habitación del niño (2005, episodio para la serie de televisión Películas para no dormir), Los crímenes de Oxford (2008) y Balada triste de 
nal. Por ejemplo, en Acción mutante la señal para emprender el secuestro de Patricia es la canción "Aires de fiesta" de Karina, sonando además en esa "máquina del tiempo" que es la jukebox. Su tono despreocupado es el contrapunto sardónico a una secuencia en la que un inesperado hombre sale de la tarta de la fiesta y causa el pánico, disparando una metralleta a diestro y siniestro. En otras ocasiones las canciones van como anillo al dedo a personajes y narrativas, especialmente en la memorable banda sonora de El día de la Bestia donde suenan Def con Dos, Extremoduro, Negu Gorriak, Eskorbuto, Siniestro Total y The Pleasure Fuckers. El estilo deathmetal en entornos subculturales enlaza perfectamente con el ritmo frenético de montaje de la película y las referencias al infierno. La comedia está servida con el personaje del heavy interpretado por Santiago Segura, pero sobre todo con la parodia de la dimensión demoníaca de ese rock "satánico y de Carabanchel".

En consonancia con su personal visión traumática del pasado español, en Muertos de risa (1999) y Balada triste de trompeta (2010) las canciones sirven, además, para ilustrar historias ambientadas en la década de los años setenta, una época derivada de los felices sesenta pero más sórdida, más crispada socialmente, menos ingenua.

Muertos de risa es la historia de una amistad que se transforma en odio ciego: una pareja de cómicos, Nino (Santiago Segura) -por sus imitaciones de Nino Bravo- y Bruno (El Gran Wyoming) se convierte en estrellas de la noche a la mañana pero, poco a poco, la rivalidad y el odio conducen a la tragedia ${ }^{4}$. En el relato, que abarca desde 1972 a 1993, la televisión más que en ninguna otra película juega un papel fundamental, en tanto en este caso se cuenta la historia desde dentro del mundo televisivo, al tiempo que vemos a José María Íñigo en Directísimo, a Chicho Ibáñez Serrador en Un, dos, tres... responda otra vez, y a otros personajes de la época (Víctor Manuel, Massiel, Moncho Borrajo....). Como ambientación temporal, pero sobre todo símbolo de esa nostalgia cínica del realizador, recupera temas de los años sesenta y setenta: "Noelia" (Algueró, Guijarro) y "Libre" (Armenteros, Herrero) interpretadas por el trasunto de Nino Bravo en un garito de mala muerte, "Killing me softly with his song" (Charles Fox, Norman Gimbel) en una paródica interpretación, presuntamente virtuosa con armonizaciones a dúo, además de otras como "Verano azul" (Gómez-Escolar, Bernaola), "Rapper's delight" (B. Edwards, N. Rodger) y "Me estoy volviendo loco" (J. Ruiz, J. Montoya). Como aportación adicional, un impagable videoclip setentero donde Wyoming y Segura hacen de Los Golfos cantando "Que pasa contigo tío" (Seijas Cabezudo, Gómez-Escolar), al más puro estilo Lazarov.

Por su parte, Balada triste de trompeta comienza en plena Guerra Civil: dos payasos actúan en un circo hasta que una compañía del ejército viene a llevárselos a filas. Javier (Carlos Areces), el hijo de uno de ellos, será uno de los protagonistas de una película cuyo telón de fondo no solo es el circo sino también el mito traumático de las dos Españas, el pasado trágico de un país

trompeta (2010). Para de la Iglesia, Baños explota su vertiente más cínica y utiliza música sinfónica al estilo melódico del cine americano, en contraste con las localizaciones castizas y los personajes populares: precisamente al situarse en el punto de vista de los personajes, la música resalta lo ridículo de las situaciones. En Muertos de risa a petición del director recurre a un octeto en los títulos de crédito, en recuerdo a la música de Nino Rota en las películas de Fellini, aunque en el resto usa una música excesiva de orquesta y piano. En otras como 800 balas echa mano de estereotipos del western o del cine de suspense en La habitación del niño. Previamente, Álex de la Iglesia colaboró con el músico Juan Carlos Cuello en Acción mutante (1992), con Battista Lena en El día de la bestia (1995), con el músico especializado en terror Simon Boswell en Perdita Durango (1997) y desde La chispa de la Vida (2011) su músico de cabecera es Joan Valent.

4 Bruno entra en el chalet de Nino y mata accidentalmente a su madre. Angulo señala que Nino se escapa de la cárcel "de la misma forma en que en 1985 lo había hecho el escritor Joseba Sarrionandia de la cárcel de Martutene, acusado de pertenencia a ETA, oculto en el interior de un bafle del equipo del cantante Imanol, que nada tuvo que ver con el asunto, tras una actuación de este en la prisión" (Angulo 2012: 54). 
colmado, hasta la actualidad, de deseos de venganza. Los créditos de inicio de Balada triste de trompeta (2010) son un magnífico ejemplo del pastiche memorístico de Álex de la Iglesia quien, con un fondo de saeta, elabora una secuencia donde se mezcla la simbología franquista -imágenes de Franco con Hitler, fusilamientos, Arias Navarro o Carmen Polo- con muy diversas imágenes de la cultura popular de la época, que van desde el Cristo de Grünewald y la Semana Santa hasta Massiel, Lola Flores, Torrebruno, los Chiripitifláuticos, Dalí, Tip y Coll e incluso López Vázquez en la cabina. La saeta en este caso es una premonición que no sólo anuncia el dolor físico y moral que mostrará la película, sino también el lado trágico de la España negra. No es el único momento en el que recurre a imágenes de archivo, pues a lo largo de la película no solamente veremos la apertura del Valle de los Caídos o el baño de Fraga en Palomares, sino también la llegada de los Beatles a España del año 1965, Massiel y Salomé en Eurovisión, la eclosión del turismo y otros muchos personajes del famoseo de la época.

Por supuesto, el momento musicalmente estelar es la inserción de la secuencia de la película de Vicente Escrivá Sin un adiós (1970), en la que Raphael canta el tema que da título a la película, "Balada triste de trompeta" (previamente, el protagonista escucha la canción por primera vez en un bar donde come una familia). La vemos, además, en el cine Luchana de Madrid, mientras Javier comienza a tener alucinaciones. En la otra secuencia "musical" más destacada, Natalia hace un playback del éxito de Marisol "Tengo el corazón contento", en el local Koyak. Al igual que en el caso anterior, un humor negro mezquino y punzante invierte el sentido literal de la canción para, de forma casi ingenua, poner sobre la mesa la trágica situación de un personaje al borde del abismo.

No sería descabellado comparar algunas de estas escenas con el cine de Quentin Tarantino, pues ambos realizan un nuevo cine de autor, collage de referencias de la cultura popular que devienen atemporales, y donde las muchas músicas utilizadas ven transformado su sentido originario, al servicio de la película. En el cine de Álex de la Iglesia, la permanente recuperación de objetos del pasado y la llamada al conocimiento de códigos es subvertida, porque los elementos sonoros resultan productos utilitarios cotidianos, convertidos en alusiones vagas al pasado. Tanto estas películas, como aquellas a las que hemos hecho referencia en este artículo, de alguna manera contribuyen a la reconstrucción de la historia del pop español aunque, como todas las películas nostálgicas, recrean la historia cercana para un consumo contemporáneo.

\section{BIBLIOGRAFÍA}

ANGULO, Jesús, SANTAMARINA, Antonio, Álex de la Iglesia. La pasión de rodar, Donostia, Filmoteca Vasca, 2012.

BENET, Vicente J., El cine español. Una historia cultural, Barcelona, Paidós Comunicación, 2012.

FLINN, Caryl, Strains of Utopia. Gender, nostalgia and Hollywood film music, Princeton, Princeton UP, 1992.

GORBMAN, Claudia, Unheard Melodies. Narrative Film Music, Bloomington, Indiana UP, 1987.

HUTCHEON, Linda, "Irony, nostalgia and the Postmodern", University of Toronto English Libray, 1998, http://www.library.utoronto.ca/utel/criticism/hutchinp.html

JAMESON, Fredric, El posmodernismo o la lógica cultural del capitalismo avanzado, Barcelona, Paidós, 1991.

TINCKNELL, Estella, "The Soundtrack Movie, Nostalgia and Consumption", Film's Musical Moments, ed. CONRICH, lan \& TINCKNELL, Estella, Edinburgh UP, 2006, pp. 132-145. 